\title{
How to Avoid Toxigenic Problems in Animal Husbandry?
}

\section{Mesterhazy A*}

Cereal Research non-profit Ltd, Hungary

*Corresponding author: Akos Mesterhazy, Cereal Research non-profit Ltd, Department of Patology and Resistance Research, Alsokikotosor 9, 6701 Szeged, Hungary, Email: akos. mesterhazy@gabonakutato.hu

\section{Commentary}

Volume 5 Issue 2

Received Date: August 31, 2020

Published Date: September 15, 2020

DOI: $10.23880 /$ oajvsr-16000197

\section{Abstract}

All mistakes in plant breeding, plant production, storage will be manifested in the animal husbandry and will become a veterinary problem with far reaching economic consequences. The managing of the field originated toxins is far not enough because the cleaning losses are high, toxin binding is only moderately effective and expensive and this is valid for the use of antibiotics. We should prevent toxin contamination in the field as far it is possible with varieties and hybrids with higher and increasing resistance, better agronomy and plant protection. A well-organized harvest (separation of the grain according toxin contamination), excellent storage facilities and management are also highly important. The veterinary side can be successful when cooperates with the breeding and production and delivers the results supporting better limits for toxins and support extensive prevention also in the government.

Keywords: Toxin Pressure; Veterinary Action; Resistance Breeding; Plant Protection; Integrated Toxin Management

\section{Introduction}

The toxigenic fungi cause heavy losses in the in the yield, but the toxic poisoning of the grain is economically far more important. They provide food safety risk in human food supply and the same is true also for the animal husbandry. The amount of the global grain mass contaminated by mycotoxins is estimated to about 210 million $t$. A significant part of the storage loss, estimated about 420 million $t$ is due to storage fungi [1]. As many toxigenic species occur, hundreds of toxins may be detected in different feedstuffs, but the main most important fungi are the Fusarium spp. (main toxins: deoxynivalenol, zearalenon, fumonisins, T-2 toxin), Aspergillus flavus (aflatoxins) and Penicillium spp. (ochratoxin A) [2]. As the veterinary consequences are heavy we should investigate the organization of the production chain so that it provides a much lower toxin pressure we have now.

\section{The Concept}

It was known for decades that the solution should be complex, the whole production chain from the breeding, plant production, plant protection, harvest and storage should be organized well to ensure the consumers and animals the excellent quality grain with a toxin contamination lower than the suggested limit values $[3,4]$. However in spite of significant efforts and scientific results the practical results are coming slowly, and far not so rapidly it was supposed 2030 years ago. Mostly, because the most important branches have a mostly independent activity without integrating the chain. This is a scientific problem, but it has its social, political, economic, an information technology causes. Therefore, the solutions should integrate the activity, otherwise the capital invested into the different branches may be lost.

\section{Management of the Toxins}

The main step is internationally the decontamination of the grains [5]. The problem is realized when the grain harvested has toxins. The process has additional costs and a yield loss is natural during the cleaning process. The specialists in Bühler AG (Zürich, $\mathrm{CH}$, personal communication) say when a cleaning process costs more loss than $20 \%$ of the outgoing grain mass, is not economical. The other problem is that the milling byproducts are used 


\section{Open Access Journal of Veterinary Science \& Research}

as animal feed. In the wheat bran the toxin contamination is often 2-3 times higher than in the flour. This makes bankruptcy in a swine production farm in several days. Last year I received samples from a $2000 \mathrm{t}$ barley lot with 6.1 $\mathrm{mg} / \mathrm{kg}$ DON. Following grain cleaning, selection for grain size, gravity screening and dehulling could reduce DON to $1.6 \mathrm{mg} / \mathrm{kg}$, but $40 \%$ of the outgoing grain is lost (Mesterhazy and Veha, 2019 unpublished). Chemical agents, feed additives like toxin binders, biological detoxification and biotransformation are also suggested [6]. Ozone treatment can also be successful [7]. The lesson is that contaminated feedstuffs should not be used for feeding purposes. The suggested limits for animal feeding of EU are very high, it needs significant decreasing of the limits. In young animals like piglets baby food quality should be secured. For this a significant part of grain is not suitable. In the feed industry the methods usual in milling industry are not used in the animal husbandry. Therefore the exposition of the animals is very high. In many cases the cleaning efficiency is not enough and the consequences of the poisoning can be observed in spite of the mass losses during cleaning accompanied by manipulation costs. The conclusion is that only healthy grain should be fed to the animals. This is also the most important task to prevent veterinary problems and economic losses.

\section{Resistant Plants}

Full resistant, immune plants are not known, but 1020 fold differences occur between cultivars in infection and toxin contamination. The high toxin contaminations are consequences of epidemics. The research in small grains verified that the higher resistance is mostly connected with a lower toxin contamination [8-10]. In wheat the resistance to different Fusarium species seems to be connected. So the breeding against $F$ graminearum resulted a similar increase to other Fusarium spp. tested. However, most of the cultivars are susceptible or highly susceptible. Among breeding lines we have so high resistance that visual symptoms are hardly to recognized and in DON 100 fold differences occur [11]. In maize the situation is similar, with the important difference that the resistance to different toxigenic species is not connected [12-14]. The methodology of the resistance testing is ready. The conclusions are as follows:

1. The preference of more resistant plants is a fundamental interest of the growers, of the animal husbandry. Therefore, all variety candidate should be qualified for resistance to disease and toxin response (the two traits are not synonyms). This is valid also for registration tests. In about three years the rate of the more resistant cultivars will increase feed safety, and cause a significant toxin reduction in the production.

2. Parallel with this work we should start and continue the breeding program to breed even higher resistant plants that could be identified among the existing cultivars. This is important because for many reasons we do not have full resistant plants, we should count with toxin contamination, and even this is significantly less than was before. We have now wheat lines that are highly resistant as shown in Figure 1, and in maize we identified also very high resistance differences in hybrids [14]. For this reason the work provides progress.

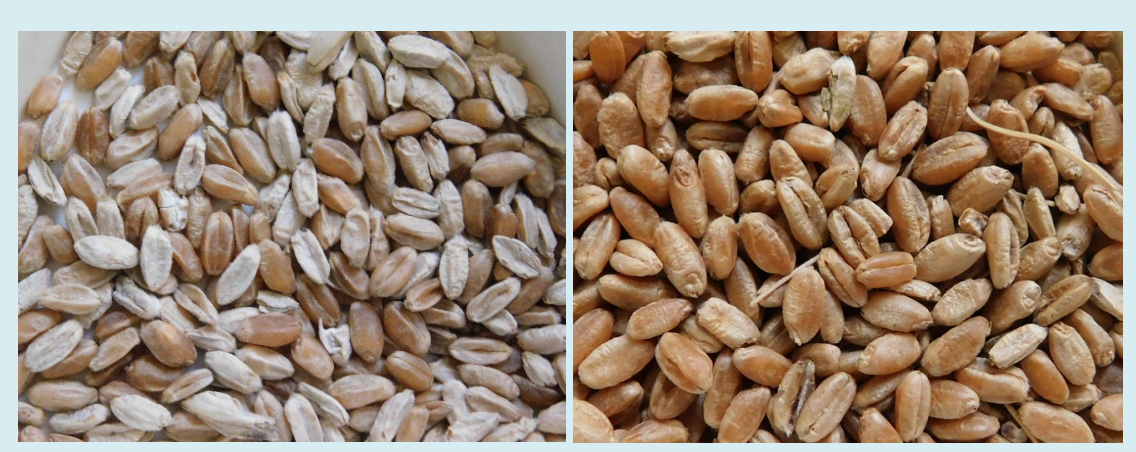

Figure 1: Highly susceptible and a highly resistant wheat line response to the same F. graminearum isolate, 2016.

As the resistance is not full, it should be supported by good agricultural practices, optimal previous crop, fungicide application (in wheat the technology is ready) [8], in maize at present we can rely only on resistance.

The decreasing toxin concentration will produce significantly less acute symptoms in animals, with the lowering immune suppression the risk of the secondary animal epidemics can also be reduced significantly. In a large swine farm (60000/year) when DON contamination is higher than $1 \mathrm{mg} / \mathrm{kg}$, the rate of mass increase was reduced by 10 $15 \%, 7-8 \%$ of the piglets died in spite of the toxin binding and continuous antibiotic treatment. When the farm was successful to receive maize at $0.2 \mathrm{mg} / \mathrm{kg}$ DON contamination, no antibiotics were necessary any more, no toxin binder should have been used, the death rate was reduced below $1 \%$ and the feed utilization increased by $10-15 \%$ (Dr. Robert Koch, veterinarian, personal communication). It would be significant to make more and more tests what 


\section{Open Access Journal of Veterinary Science \& Research}

is really happening, how the different animal species and varieties react to different toxins and in every country would be important to revise the toxin limits for feedstuffs and composite feeds. The multitoxin problem is living.

The veterinary side has also very important tasks, even the quality of the grain is not in their hands. The veterinarians should have up to date education what the toxin problems are, what are the symptoms, how to cure them. They are the persons who can convince the stakeholders to secure healthy feed and so practice a pressure on the agricultural production and trade to be able to secure the necessary quality of the feed stuffs. It is similarly important to concentrate more on the research, where really the toxin limits are that are yet tolerable. Surely, for a good quality feed it should be paid more, but this can be spared on the damage, additional costs, so the compatibility of the given farm can be increased. Of course, there are research data, but we need much more and especially the multitoxin problem is very alive [15]. I think the veterinary sciences should also build new and more effective bridges to the practical husbandry, and the cooperation with plant breeding and plant production is as important as the influencing governmental decisions in the good direction in limit values and plant registration.

As globally very high amount will be destroyed during harvest and storage, it is eminent interest to keep them healthy. In the well managed storage system the loss should not be more than 2-3 \% that comes respiration of the grain. The technology is given. It is very important that feed toxin limits should be updated worldwide. And an agriculture is also needed that can supply the high quality needs in toxins and other relations.

\section{Acknowledgements}

I would thank the support for Ministry for Innovation and Technology No. 2020-4.1.1-TKP2020

\section{References}

1. Mesterhazy A, Oláh J, Popp J (2020) Losses in the Grain Supply Chain: Causes and Solutions. Sustainability 12(6): 2342

2. Leonard KJ, Bushnell WR (2003) Fusarium head blight of wheat and barley. APS Press St. Paul. MN, USA, pp: 511

3. Leslie JF, Logrieco AF (2014) Mycotoxin reduction in grain chains. Wiley Blackwell, Ames, Chichester, Oxford, pp: 352.

4. Logrieco AF, Visconti A (2014) An introduction to the MycoRed project. In: Leslie JF, Logrieco AF, (Eds.), Mycotoxin reduction in grain chains. Wiley Blackwell, Ames, Chichester, Oxford, pp: 352.
5. Colovic R, Puvaca N, Cheli F, Avantaggiato G, Greco D, et al. (2019) Decontamination of mycotoxin-contaminated feedstuffs and compound feed. Toxins 11(11): 617.

6. Cheli F (2020) Mycotoxin contamination management tools and efficient strategies in feed industry. Toxins 12(8): 480.

7. Conte G, Fontanelli M, Galli F, Cotrozzi L, Pagni L, et al. (2020) Mycotoxins in feed and food and the role of ozone in their detoxification and degradation: an update. Toxins 12(8): 486.

8. Mesterhazy A, Varga M, György A, Lehoczki-Krsjak S, Tóth B (2018) The role of adapted and non-adapted resistance sources in breeding resistance of winter wheat to Fusarium head blight and deoxynivalenol contamination. World Mycotoxin Journal 11(4): 539557.

9. MesterhazyA,Gyorgy A,Varga M,TothB(2020) Methodical considerations and resistance evaluation against $F$. graminearum and $F$. culmorum head blight in wheat. The influence of mixture of isolates on aggressiveness and resistance expression. Microorganisms 8(7): 1036

10. Toth B, Gyorgy A, Varga M, Mesterhazy A (2020) The Influence of the Dilution Rate on the Aggressiveness of Inocula and the Expression of Resistance against Fusarium Head Blight in Wheat. Plants 9(8): 943.

11. Mesterházy Á, Bartók T, Kászonyi G, Varga M, Tóth B, et al, (2005) Common resistance to different Fusarium spp. causing Fusarium head blight in wheat. European J Plant Path 112: 267-281.

12. Szabó B, Tóth B, Toldiné É, Varga M, Kovacs N, et al. (2018) A New Concept to Secure Food Safety Standards against Fusarium spp. and Aspergillus flavus and Their Toxins in Maize. Toxins 10(9): 372.

13. Mesterházy A, Lemmens M, Reid LM (2012) Breeding for resistance to ear rots caused by Fusarium spp. in maize a review. Plant Breeding 131: 1-19.

14. Mesterhazy A, Toldine Toth E, Szel S, Varga M, Toth B (2020) Resistance of maize hybrids to Fusarium graminearum, F. culmorum, and $F$. verticillioides ear rots with toothpick and silk channel inoculation, as well as their toxin production. Agronomy 10(9): 1283

15. Szabó A, Szabó-Fodor J, Fébel H, Mézes M, Balogh K, et al. (2018) Individual and combined effects of fumonisin B1, deoxynivalenol and zearalenone on the hepatic and renal membrane lipid integrity of rats. Toxins 10(4): 4.

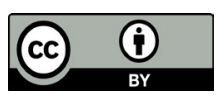

